\title{
THE ASSOCIATION BETWEEN TRAUMATIC BRAIN INJURY AND GLIOMAGENESIS AND ITS SPECIAL ROLE IN GLIOBLASTOMA MULTIFORME PATHOGENESIS: A REVIEW
}

\author{
NIKOLAOS ANDREAS CHRYSANTHAKOPOULOS ${ }^{1}$, PANAGIOTIS ANDREAS CHRYSANTHAKOPOULOS
}

${ }^{1}$ Department of Pathological Anatomy, Medical School, University of Athens, Athens, Greece. ${ }^{2}$ Department of Neurosurgery, Military Hospital of Athens, Athens, Greece. Email: nikolaos_c@hotmail.com/nchrysant@med.uoa.gr

Received: 05 December 2020, Revised and Accepted: 25 January 2021

\section{ABSTRACT}

Gliomas are the most common primary and aggressive intracranial tumors, represent $80 \%$ of malignant brain tumors, and despite the fact that are relatively rare tumors are responsible for significant mortality and morbidity. Glioblastoma multiforme (GBM) or diffuse astrocytoma, WHO grade IV, is the most common and aggressive primary central nervous system malignancy, represents $45 \%$ of all gliomas, shows an average incidence of $3.19 / 100,000$ individuals, its median age of diagnosis is 64 years, and the median survival is 15 months as the 5-year relative survival is $5 \%$. Previous studies have investigated the possible role of genetic and environmental factors in GBM pathogenesis; however, the majority of GBM cases were sporadic and certain risk factors have not been detected. GBM is divided into primary and secondary subtypes which develop through different genetic pathways, affect patients at different ages, and have differences in clinical outcomes, as show a great morphological and genetic heterogeneity. The role of traumatic brain injury (TBI) in GBM formation has been investigated in many previous reports which have hypothesized that TBI may predispose to gliomagenesis; however, the outcomes were highly controversial. Some of those researches have proposed a supposed pathogenesis model that involves a post-traumatic inflammation, stem and progenitor cell transformation, and gliomagenesis. Other similar studies have involved transcription factors associated with TBI such as p53, hypoxia-inducible factor-1a (HIF-1a), and c-Myc. On the other hand, the possibility of a preexisting tumor rather than a trauma-induced tumor is very possible in such cases.

Keywords: Gliomas, Glioblastoma, Signaling Pathways, Inflammation.

(C) 2021 The Authors. Published by Innovare Academic Sciences Pvt Ltd. This is an open access article under the CC BY license (http://creativecommons org/licenses/by/4.0/) DOI: http://dx.doi.org/10.22159/ijms.2021v9i2.40457. Journal homepage: https://innovareacademics.in/journals/index.php/ijms

\section{INTRODUCTION}

Gliomas are primary brain tumors, and classified according to their supposed origin cell, as astrocytic tumors (astrocytoma, anaplastic astrocytoma, and glioblastoma), oligodendrogliomas, ependymomas, and mixed gliomas [1]. They are the most common primary and aggressive central nervous system tumors which account for almost $80 \%$ of all malignant primary brain tumors $[1,2]$. In general, gliomas are more common in males than females, with the exception of pilocytic astrocytoma, which occurs at similar rates in males and females [3]. Anaplastic astrocytoma and glioblastoma multiforme (GBM) increase in incidence with age, peaking in the 75-84 age group. Oligodendrogliomas and oligoastrocytomas are the most common in the 35-44 age group [4]

GBM or diffuse astrocytoma, WHO grade IV [5], is the most malignant and frequent type of primary astrocytomas, as accounts for more than $60 \%$ of all brain tumors in adults [6], is characterized by extremely poor prognosis, despite developments in molecular Biology and genetics and new anti-neoplasmatic treatments and shows a great morphological and genetic heterogeneity, whereas its median survival is about 14-15 months after its diagnosis $[7,8]$.

GBM's global incidence is $<10 / 100,000$ individuals [8], accounts for $50 \%$ of all gliomas age but the peak incidence concerns individuals between ages 55 and 60 [9], is the $3^{\text {rd }}$ principal cause of death from cancer in individuals 15 and 34 years of age [10], whereas the GBM incidence ratio is higher in males than in females $[8,9]$.

Brain neoplasms etiology has not yet been clarified as no underlying carcinogenetic factors have been identified. Until now the only confirmed risk factor is exposure to high dose ionizing radiation [11,12]; however, the overall risk of developing GBM following radiotherapy is $2.5 \%$ [13].
Extensive retrospective cohort data showed a higher risk of glioma in pediatric populations after exposure to therapeutic intracranial radiation. Data in adults are more limited but showed increased risk in certain groups exposed to radiation. No evidence was found between risk of developing GBM and routine exposure to diagnostic radiation in both children and adults [14].

Furthermore, patients who received treatment for acute lymphoid leukemia (ALL) were more prone to develop GBM, as a result of complications arising from the leukemia or the chemotherapeutic agents used to treat ALL [13]. No conclusive association has been found between GBM and environmental factors such as smoking, dietary risk factors, cell phones or electromagnetic field, human cytomegalovirus infection, occupational risk factors, and pesticide exposure [1,12,15-17]. Few studies have shown the possible role of ovarian steroid hormones in development of GBM [18]. It has also been proposed that infections and allergic diseases may have a protective effect for GBM that may be due to the activation of immune surveillance mechanism [5,11]. Gliomas also tend to run in families but the susceptibility gene is still unidentified [11].

Genetic predisposition has been observed only in 5-10\% of cases [15] Family history has been shown to be associated with an increased risk of GBM. Recent genome-wide association studies have indicated single nucleotide polymorphisms (SNPs) that can increase the predisposition to glioma development [19-24]. Such a significant SNP is located on chromosome 8q24.21, within the locus of a long non-coding RNA named CCDC26, which increases glioma risk approximately 5 times [19-21]. Infrequent genetic diseases such as neurofibromatosis type 1 and type 2, and tuberous sclerosis, were found to be associated with increased GBM incidence $[11,12,16]$. Environmental risk factors in GBM development remain poorly defined, as already has been mentioned, with the exception of exposure to ionizing radiation. Another possible risk factor for gliomagenesis is traumatic brain injury (TBI) [25-27]. 
The present review aims to present an overview of the current knowledge regarding the pathogenesis of GBM mainly focusing on the possible role of previous traumatic brain injuries and its association with GBM development, according to the international literature".

\section{EPIDEMIOLOGICAL RESEARCH}

Several epidemiological studies have attempted to investigate the possible association between previous TBI and GBM development; however, the findings were controversial.

TBI-induced gliomas incidence cannot be determined as post traumatic gliomas have not been included in brain tumors statistical reports, except from epidemiological studies. Munch et al. [28] carried out a nationwide cohort study and found that the incidence of post-traumatic glioma among individuals with a brain trauma was $3 / 10,000$. However, the estimated incidence was based on a special individual group and not to the entire population. Moreover, post-traumatic glioma incidence is difficult to be assessed due to the frequently significant time period between TBI and glioma development. The authors investigated over 400,000 individuals and recorded no association between TBI and risk of malignant glioma during the first 4 years after TBI. On the contrary, the same research showed that TBI was associated with long-term protection from malignant gliomas. Inskip et al. [29] assessed the incidence of brain and other intracranial tumors following head trauma in a cohort of 228,055 Danish hospitalized individuals and recorded a slightly increased overall incidence of intracranial tumors, but no association between head trauma and malignant astrocytic tumors, such as malignant astrocytoma and GBM. A limitation of this study was the short follow-up time. Another population-based cohort study which was based on over 300,000 individuals who had documented TBI observed 400 cases of brain tumors, but no overall association between TBIs and intracranial tumors was recorded [30]. A proportion of those cases were excluded because they occurred within the $1^{\text {st }}$ year after the TBI. However, the outcomes did not refer the specific risks for malignant astrocytic tumors.

A similar, population-based study in Taiwan aimed to assess the risk of having a diagnosis of malignant brain tumors within 3 years after a TBI [31]. The investigators observed an increased risk for not otherwise specified malignant brain tumors and suggested a positive association between TBI and the relatively short-term development of brain malignant neoplasms, after adjusting for sociodemographic parameters. The authors found that the risk of developing an intracranial malignancy within 3 years of TBI was 4.67 times greater for individuals with TBI compared to those without injury. The same report also showed a statistically significant association between TBI severity and brain tumor development [31]. Monteiro et al. [32] observed that individuals with TBI showed an increased risk of developing brain tumors and they also found that after adjusting for age, gender, and schooling, two or more brain injuries could lead to an association between brain injury severity and frequency and subsequent tumor development.

A multicenter case-control study in a group [33] of 801 children showed that the odds ratio of developing a primary brain tumor after previous TBI was 1.4 and was remained after adjusting for age, gender, and location. Another finding was that multiple brain injuries may be much more likely to cause a primary tumor than a single injury and was also recorded that the severity of the injury is possible to be associated with the risk of developing a brain tumor.

Controversial outcomes recorded after performing few case-control studies which investigated the risk for malignant astrocytoma/ glioma after a head trauma and showed positive [34,35] and invalid associations [36,37].

Previous case reports proposed the possible pathogenesis of GBMs which occurred up to 20 years later at the location of TBIs as a result of neoplastic transformation of damaged astrocytes [25-27,38-42]. Similarly, other case report studies suggested that acquired head injuries, which may occur as a result of a brain contusion, may predispose to the appearance of malignant gliomas [26,37,39,43-50], whereas a definite evidence for a possible causative role of TBI in gliomas and GBMs pathogenesis has been suggested by a small number of case report studies $[41,46]$.

The possible association between TBI and gliomagenesis has not been resolved yet [51], as only a few documented cases have been demonstrated that association. Moreover, it was necessary to be established some objectively criteria for a glioma to be considered as a post-traumatic. Zhou [27], based on previous investigators, reported the following criteria for post-traumatic glioma determination: (1) Good health condition of the individual before being injured, (2) damage must be serious enough to cause brain injury and to trigger a secondary repair procedure, (3) tumor and injury must be concerned the same location, (4) it should be confirmed the histopathological environment of tumor and brain injury, (5) the time difference between brain injury and the appearance of the tumor should be more than a year, as a longer latent period is considered to be a stronger evidence of a causal relation, (6) the trauma should occur from an external force, (7) clinical signs such as bleeding, scars, and secondary edema must be induced by the tumor and not the injury, and (8) tumor tissue should be a direct continuation of the traumatic scar, and not be adjacent in it or separated by a healthy section. Anselmi et al. [25] reported two cases who developed brain gliomas in the scar of a previous TBI and met the mentioned criteria for a causal relationship between TBI and glioma development. Moreover, other investigators have suggested more pathologic criteria for the diagnosis of a post-traumatic glioma, such as a computed tomography (CT) or magnetic resonance imaging (MRI) immediately after the TBI that displays evidence of brain injury but no tumor and histopathological confirmation [52].

\section{DISCUSSION}

\section{Possible pathogenetic mechanisms}

\section{Recruitment of neural stem cells (NSCS) to injury location}

Adult NSCs are located to the sub-ventricular zone of the lateral ventricles and the sub-granular zone of the hippocampal dentate gyrus [53], whereas NSCs or progenitor cells may also located at cortical areas [54]. NSCs in neurogenic regions are responsible for the generation of neurons, astrocytes, and oligodendrocytes. In case of a TBI, those NSCs and descendant progenitor cells migrate chemotactically to the brain injury locations and contribute to the repair and recovery procedures [55-59]. That described chemoattraction-mediated migration has been detected in several injuries which is characterized by ischemia and demyelination [55]

A case report study showed that the examined cases developed GBM at their brain injury location several years later and suggested an hypothesis that in some individuals, an underlying biological susceptibility predisposes them to gliomagenesis after brain trauma. With regard to the possible pathogenic mechanisms they proposed that the inflammatory reaction which is activated after TBI is related to the oncogenic transformation of NSCs and progenitor cells that migrate chemotactically to the injured region in response to inflammation [60].

It has been proven that chronic inflammation is a crucial predisposing factor for many solid tumors in various organs [61]. However, such an association has not been investigated in gliomagenesis because of the special brain immune properties. The authors suggested that in a subset of patients, brain post-traumatic inflammation may predispose neural cells toward oncogenic transformation and glioma appearance. Therefore, it is possible that GBM may arise from NSCs or progenitor cells transformation as those cells migrate to the injury location to repair tissue damage [60].

It has been reported that several neural cell types that migrate to TBI sites are capable of undergoing oncogenic transformation, such as astrocytes from injured brain tissue which demonstrate long-term activity, suggesting the possibility of a return to multipotent stem cell under certain conditions $[62,63]$. Based on the observation that neurogenic regions in the brain are sensitive to chemical oncogenesis, it has been suggested the NSCs oncogenic potential $[54,64,65]$. 
Moreover, experimental studies have indicated that even terminally differentiated brain cells, such as neurons and astrocytes, can contribute to GBM development by undergoing dedifferentiation induced by genetic alterations $[66,67]$, whereas ependymal cells, which cover the inner walls of the ventricles, may also proliferate and differentiate into neuroblasts and astrocytes after TBI in mice and humans $[68,69]$.

Experimental models implicate overexpression of oncogenes and inactivation of tumor suppressor genes in NSCs suggesting that they can lead to GBM development [53]. That assumption has been supported by the observation that GBMs have been frequently observed in the periventricular zone or in direct contact with the subventricular zone [70-72].

\section{Role of astrocytes}

Previous reviews, based on histopathological findings, showed that after a structural brain injury, reactive astrocytes are responsible for a localized inflammatory reaction which leads to astrogliosis and glial scar formation [73-75]. After brain parenchyma damage, occurs reactive astrocytes proliferation, alteration of their morphology, and migration to the injury location, where are able to promote or inhibit the generation of neurons from NSCs and progenitor cells $[62,76]$.

Adult periventricular NSCs give rise to glia cells, astrocytes and oligodendrocytes, are also activated in astrogliosis as an element of the repair mechanism in structural brain injury [74].

Periventricular NSCs and reactive astrocytes express glial fibrillary acidic protein [77] which is also expressed in most astrocytic tumors, GBM included in the study. It has been suggested that GBMs can be developed from astrocytic origin cells and oligodendrocyte progenitor cells, dependent on the subtypes $[77,78]$.

Munch et al. [28], in a nationwide cohort study reported that any condition which leads to astrogliosis and includes any type of structural brain injury which causes brain parenchyma damage, may be associated with long-term risk especially for malignant astrocytic tumors. The authors investigated the potential association between structural brain injury caused by trauma, which causes reactive astrogliosis and longterm risk for malignant tumor of astrocytic origin (WHO grades III and IV), and observed no association between structural brain injury and malignant astrocytic tumors within the first 5 years of follow-up. On the contrary, it was reported a protective effect of astrogliosiscausing injuries 5 or more years after the structural brain injury [28].

\section{Inflammatory reaction at brain injury location}

It has been documented that at the brain injury location an inflammatory reaction occurs [79-82]. During the acute post-trauma period, a sequential mobilization of resident brain microglia and myeloid inflammatory cells to the injury location has been detected. Peripheral inflammatory cells such as neutrophils, monocytes, and eosinophils migrate and are recruited to the injury location within hours and can remain for extended time periods [79]. Those inflammatory cells can contribute to oncogenesis due to production of reactive oxygen species (ROS) and reactive nitrogen species, which have mutagenic properties, or due to growth factors expression of cytokines and chemokines that have mitogenic effects on NSCs and progenitors cells, in addition to elongating the inflammatory reaction $[80,81]$. At TBI location, inflammatory cytokines such as interleukin (IL)-1, IL-6, IL-8, IL-10, tumor necrosis factor- $\alpha$, and monocyte chemoattractant protein-1 (MCP-1) are up-regulated and contribute to the myeloid immune cells recruitment [81]. IL-4 and IL-13 are able to activate the IL4 Ra receptor on immune system cells, which leads to similar downstream responses, and results in the release of chemoattractants such as eotaxin and MCP-1. Those chemotactic proteins lead to the migration and recruitment of eosinophils and monocytes into the injury location $[81,83]$. Moreover, it has been proven that SNPs in IL-13 and IL-4Ra may contribute to an increased risk of GBM development [84].

Regarding the role of eosinophils, they are implicated in the initiation and progression of GBM [85]. Activated eosinophils produce eosinophil-derived neurotoxin (EDN, RNase 2), eosinophil cationic protein (RNase 3), and eosinophil protein $\mathrm{X}$ that have been experimentally shown to cause cellular damage in neural tissues during their degranulation $[85,86]$. EDN has also been identified as a toll-like receptor-2 (TLR2) ligand that can promote in vivo activation of murine dendritic cells (DCs) [87]. In experimental GBM models, TLR2-ligands have been found to induce an influx of tumor-infiltrating immune cells (DCs, CD8+ T effector cells) and significant tumor regression $[88,89]$, which raises the possibility that EDN may operate comparatively.

Moreover, eosinophil peroxidases generate ROS, which may lead to mutagenesis $[61,85,90]$.

Inflammation is responsible for healing wounds, maintaining tissue homeostasis and is involved in tumor pathogenesis, as induce DNA damage and genetic instability. Especially, chronic inflammation may cause malignant transformation through mutations or epigenetic pathways, as can activate various oncogenes, such as c-Myc which is involved in inflammatory reactions and is often deregulated, and malignant transformation. It is also associated with increased cellular proliferation, whereas can lead to induction of p53-dependent apoptosis following DNA damage [91]. c-Myc expression may be a marker of brain trauma as has been detected by immunohistochemical examination of rat brains [92]. p53 protein induces neuronal apoptosis and is responsible for regeneration after TBI, due to the activation of the p53-induced death domain protein [93].

The association between trauma and inflammation is more promptly recognized in non-brain tumors such as pancreas and liver. After an acute injury an acute inflammation occurs $[80,82]$ and implicates an oxidative cascade and inflammatory cells production. However, this phase is temporary, as in some cases exists a balance between the immune/inflammatory and regenerative responses, which if it modifies will increase the probability of malignant transformation [82].

Injury and inflammation have been associated with various types of cancer or other recurrent trauma. However, its implication in GBM development has not been confirmed by epidemiological studies [94]

Xiong et al. [95] used animal models for investigating TBI and recorded oxidative stress and calcium homeostasis disruption, but no brain cancer.

Arif et al. [96] examined GBM and its associations with c-Myc, hypoxiainducible factor-1a (HIF-1a), and p53, FOX03, STAT3, and AP2, and other transcription factors that regulate the transformed phenotype. It was reported that GBM obtains metabolic reprogramming, and that the voltage-dependent anion channel 1 (VDAC1), a mitochondrial protein that controls cell energy and metabolic homeostasis, could be silenced to invert the reprogrammed metabolism. VDAC1 reduction could modify transcription factor profiles, as the expression levels of transcription factors such as p53, HIF-1a, and c-Myc were mostly affected, as led to an increase in p53 expression and a decrease in HIF-1a and c-Myc expression, whereas could lead to normalization of malignant functions such as cell proliferation, loss of differentiation, and aerobic glycolysis. Those transcription factors are involved in the regulation of cell metabolism, growth, proliferation, and differentiation, therefore regulate the expression of several molecules and signaling pathways which maintain the glycolytic metabolism. It is possible that regulation of VDAC1 and the mentioned transcription factors may be involved in TBI and metabolic reprogramming and should be investigated as factors of a possible association between TBI and GBM pathogenesis [92,93,97].

HIF-1a is a transcriptional regulator of cellular and developmental response to hypoxia and has been proposed that involved in the regenerative treatment of TBI [97], whereas has also been used to treat brain edema and disruption of the blood-brain barrier in patients with TBI [98].

After occurrence of TBI the Warburg effect and HIF-1a activation in inflammatory reactions may be related to each other [99-101]. HIF-1a and the c-Myc oncogene play a role in inflammation. Therefore, it has 
been hypothesized that these transcription factors and inflammation have a function in the development of GBMs after TBI. Trauma-associated gliomagenesis may be explained by TBI-induced inflammation, which leads to malignant transformation of adjacent neural progenitor cells, as already has mentioned [60]

Animal models have been used for TBI investigations $[82,92,93,95-98,100,101]$; however, no brain cancers were initiated by skull trauma in these laboratory animals. An explanation could be the long period which is needed for such a follow-up.

A possible mechanism suggested that TBI may alter the energy metabolism of the brain by disorganizing the transduction pathways and calcium transport into mitochondrial. Consequently, it is possible that the induction of oxidative stress and the disorganization of cellular calcium homeostasis play crucial roles in TBI [95].

\section{CONCLUSION}

Epidemiological studies have not shown a definitive association between TBI and increased risk of developing GBM, finding that could reflect the fact that the association, if it exists, is not a direct one, which means that there must be additional factors, as co-factors, involved in the etiology of glioma. Moreover, large study populations are mandatory because of the relatively low prevalence of brain tumors and the low incidence of head injuries experimental studies have proposed that trauma can act as a co-carcinogen factor in cancer initiation, finding that corresponds to Knudson's theory of "Two Hits." It is possible that an underlying susceptibility in a subset of individuals with TBI may predispose them to gliomagenesis. Three models that must be investigated include neuroinflammation and mutagenesis in NSCs and progenitor cells which are recruited to the injury location, the influence of chronic inflammation, and the influence of astrocytic proliferation after TBI. It is required that the examined association should be confirmed by additional experimental researches using modern medical technologies such as CT/MRI after a brain trauma.

\section{REFERENCES}

1. Agnihotri S, Burrell KE, Wolf A, Jalali S, Hawkins C, Rutka JT, et al. Glioblastoma, a brief review of history, molecular genetics, animal models and novel therapeutic strategies. Arch Immunol Ther Exp 2013;61:25-41.

2. Schwartzbaum JA, Fisher JL, Aldape KD, Wrensch M. Epidemiology and molecular pathology of glioma. Nat Clin Pract Neurol 2006;2:494-503.

3. Gigineishvili D, Shengelia N, Shalashvili G, Rohrmann S, Tsiskaridze A, Shakarishvili R. Primary brain tumour epidemiology in Georgia: First year results of a population based study. J Neurooncol 2013;112:241-6.

4. Dubrow R, Darefsky AS. Demographic variation in incidence of adult glioma by subtype. United States, 1992-2007. BMC Cancer 2011:11:325.

5. Jovčevska I, Kočevar N, Komel R. Glioma and glioblastoma-how much do we (not) know? Mol Clin Oncol 2013;1:935-41.

6. Rock K, McArdle O, Forde P, Dunne M, Fitzpatrick D, O'Neill B, et al. A clinical review of treatment outcomes in glioblastom multiforme the validation in a non-trial population of the results of a randomised Phase III clinical trial: Has a more radical approach improved survival? Br J Radiol 2014;85:729-33

7. Ohka F, Natsume A, Wakabayashi T. Current trends in targeted therapies for glioblastoma multiforme. Neurol Res Int 2012;2012:878425.

8. Thakkar JP, Dolecek TA, Horbinski C, Ostrom QT, Lightner, BarnholtzSloanet JS, et al. Epidemiologic and molecular prognostic review of glioblastoma. Cancer Epidemiol Biomark Prev 2014;23:1985-96.

9. Ohgaki H, Kleihues P. Epidemiology and etiology of gliomas. Acta Neuropathol 2005;109:93-108.

10. Salcman M. Epidemiology and factors affecting survival. In Apuzzo ML, editor. Malignant Cerebral Glioma Neurosurgical Topic Series. Vol. 3. Park Ridge: American Association of Neurological Surgeons; 1990. p. 95-110.

11. Bondy ML, Scheurer ME, Malmer B, Barnholtz-Sloan JS, Davis FG, Il'yasova D, et al. Brain tumor epidemiology: Consensus from the brain tumor epidemiology consortium. Cancer 2008;113:1953-68.
12. Ohgaki H. Epidemiology of brain tumors. Methods Mol Biol 2009;472:323-42.

13. Salvati M, Frati A, Russo N, Caroli E, Polli FM, Minniti G, et al. Radiation-induced gliomas: Report of 10 cases and review of the literature. Surg Neurol 2003;60:60-7.

14. Prasad G, Haas-Kogan DA. Radiation-induced gliomas. Expert Rev Neurother 2009;9:1511-7.

15. Fisher JL, Schwartzbaum JA, Wrensch M, Wiemels JL. Epidemiology of brain tumors. Neurol Clin 2007;25:867-90.

16. Adamson C, Kanu OO, Mehta AI, Di C, Lin N, Mattox AK, et al. Glioblastoma multiforme: A review of where we have been and where we are going. Expert Opin Investig Drugs 2009;18:1061-83.

17. Omuro A, DeAngelis LM. Glioblastoma and other malignant gliomas: A clinical review. J Am Med Assoc 2013;310:1842-50.

18. Kabat GC, Etgen AM, Rohan TE. Do steroid hormones play a role in the etiology of glioma? Cancer Epidemiol Biomarkers Prev 2010;19:2421-7.

19. Rajaraman P, Melin BS, Wang Z, McKean-Cowdin R, Michaud DS, Wang SS, et al. Genome-wide association study of glioma and metaanalysis. Hum Genet 2012;131:1877-88.

20. Shete S, Hosking FJ, Robertson LB, Dobbins SE, Sanson M, Malmer B, et al. Genome-wide association study identifies five susceptibility loci for glioma. Nat Genet 2009;41:899-904.

21. Simon M, Hosking FJ, Marie Y, Gousias K, Boisselier B, Carpentier C, et al. Genetic risk profiles identify different molecular etiologies for glioma. Clinl Cancer Res 2010;16:5252-9.

22. Wibom C, Ghasimi S, Van Loo P, Brännström T, Trygg J, Lau C, et al. EGFR gene variants are associated with specific somatic aberrations in glioma. PLoS One 2012;7:e47929.

23. Wrensch M, Jenkins RB, Chang JS, Yeh RF, Xiao Y, Decker PA, et al. Variants in the CDK N2B and RTEL1 regions are associated with highgrade glioma susceptibility. Nat Genet 2009;41:905-8.

24. Yang TH, Kon M, Hung JH, Delisi C. Combinations of newly confirmed Glioma-Associated loci link regions on chromosomes 1 and 9 to increased disease risk. BMC Medical Genomics 2011;4:63.

25. Anselmi E, Vallisa D, Bertè R, Vanzo C, Cavanna L. Post-traumatic glioma: Report of two cases. Tumori 2006;92:175-7.

26. Chrysanthakopoulos NA, Chrysanthakopoulos PA. Potential risk factors of glioblastoma multiforme in Greek adults: A case-control study J Clin Med Res 2020;1:1-17.

27. Zhou B, Liu W. Post-traumatic glioma: Report of one case and review of the literature. Int J Med Sci 2010;7:248-50.

28. Munch TN, Gørtz S, Wohlfahrt J, Melbye M. The long-term risk of malignant astrocytic tumors after structural brain injury--a nationwide cohort study. Neuro Oncol 2015;17:718-24.

29. Inskip PD, Mellemkjaer L, Gridley G, Olsen JH. Incidence of intracranial tumors following hospitalization for head injuries (Denmark). Cancer Causes Control 1998;9:109-16.

30. Nygren C, Adami J, Ye W, Bellocco R, af Geijerstam JL, Borg J, et al. Primary brain tumors following traumatic brain injury--a populationbased cohort study in Sweden. Cancer Causes Control 2001;12:733-7.

31. Chen YH, Keller JJ, Kang JH, Lin HC. Association between traumatic brain injury and the subsequent risk of brain cancer. J Neurotrauma 2012;29:1328-33.

32. Monteiro GT, Pereira RA, Koifman RJ, Koifman S, Head injury and brain tumours in adults: A case-control study in Rio de Janeiro, Brazil. Eur J Cancer 2006;42:917-21.

33. Gurney JG, Preston-Martin S, McDaniel AM, Mueller BA, Holly EA. Head injury as a risk factor for brain tumors in children: Results from a multicenter case-control study. Epidemiology 1996;7:485-9.

34. Zampieri P, Meneghini F, Grigoletto F, Gerosa M, Licata C, Casentini L, et al. Risk factors for cerebral glioma in adults: A case-control study in an Italian population. J Neuro Oncol 1994;19:61-7.

35. Preston-Martin S, Pogoda JM, Schlehofer B, Blettner M, Howe GR, Ryan P, Menegoz F, et al. An international case-control study of adult glioma and meningioma: The role of head trauma. Int J Epidemiol 1998;27:579-86.

36. Hu J, Johnson KC, Mao Y, Guo L, Zhao X, Jia X, et al. Risk factors for glioma in adults: A case-control study in northeast China. Cancer Detect Prev 1998;22:100-8.

37. Hochberg F, Toniolo P, Cole P. Head trauma and seizures as risk factors of glioblastoma. Neurology 1984;34:1511-4

38. Magnavita N, Placentino RA, Mei D, Ferraro D, Di Trapani G. Occupational head injury and subsequent Glioma. Neurol Sci 2003;24:31-3

39. Moorthy RK, Rajshekhar V. Development of glioblastoma multiforme following traumatic cerebral contusion: Case report and review of 
literature. Surg Neurol 2004;61:180-4

40. Mrowka R, Bogunska C, Kulesza J, Bazowski P, Wencel T. Grave cranio-cerebral trauma 30 years ago as cause of the brain glioma at the locus of the trauma particulars of the case. Zen Tralbl Neurochir 1978;39:57-64.

41. Sabel M, Felsberg J, Messing-Junger M, Neuen-Jacob E, Piek J. Glioblastoma multiforme at the site of metal splinter injury: A coincidence? Case report. J Neurosurg 1999;91:1041-4.

42. Witzmann A, Jellinger K, Weiss R. Glioblastoma multiforme developing after a gunshot injury of the brain. Neurochir (Stuttg) 1981;24:202-6.

43. Annegers JF, Laws ER Jr., Kurland LT. Head trauma and subsequent brain tumours. Neuro Surg 1976;4:203-6.

44. Coskun S, Coskun A, Gursan N, Aydin MD. Post-traumatic glioblastoma multiforme: A case report. Eur J Med 2011;43:50-3.

45. Henderson RD, Campbell SF. Head trauma and brain tumours revisited. J Clin Neurosci 2000;7:262-4.

46. Henry PT, Rajshekhar V. Post-traumatic malignant glioma: Case report and review of litera-ture. Br J Neurosurg 2000;14:64-7.

47. Hill-Felberg SJ, McIntosh TK, Oliver DL, Raghupathi R, Barbarese E. Concurrent loss and proliferation of astrocytes following lateral fluid percussion brain injury in the adult rat. J Neurosci Res 1999;57:271-9.

48. Kernie SG, Erwin TM, Parada LF. Brain remodeling due to neuronal and astrocytic proliferation after controlled cortical injury in mice. J Neuroci Res 2001;66:317-26.

49. Manuelidis EE. Glioma in trauma. In: Minckler J, editor. Pathology of the Nervous System. Vol. 2. New York: McGraw-Hill; 1978. p. 2237-40.

50. Perez-Diaz C, Cabello A, Lobato RD, Rivas JJ, Cabrera Oligodendrogliomas arising in the scar of a brain contusion. Surg Neurol 1985;24:581-6.

51. Han Z, Du Y, Qi H, Yin W. Post-traumatic malignant glioma in a pregnant woman: Case report and review of the literature. Neurol Med Chir (Tokyo) 2013;53:630-4.

52. Candolf M, Curtin JF, Nichols WS, Muhammad AK, King GD, Pluhar GE, et al. Intracranial glioblastoma models in preclinical neurooncology: Neuropathological characterization and tumor progression. J Neuro Oncol 2007;85:133-48.

53. Modrek AS, Bayin NS, Placantonakis DG. Brain stem cells as the cell of origin in glioma. World J Stem Cells 2014;6:43-52.

54. Sanai N, Alvarez-Buylla A, Berger MS. Neural stem cells and the origin of gliomas. N Engl J Med 2005;353:811-22.

55. Elvira G, García I, Gallo J, Benito M, Montesinos P, Holgado-Martin E, et al. Detection of mouse endogenous Type B astrocytes migrating towards brain lesions. Stem Cell Res 2015;14:114-29.

56. Goings GE, Sahni V, Szele FG. Migration patterns of subventricular zone cells in adult mice change after cerebral cortex injury. Brain Res 2004;996:213-26

57. Jin K, Sun Y, Xie L, Peel A, Mao XO, Batteur S, et al. Directed migration of neuronal pre-cursors into the ischemic cerebral cortex and striatum. Mol Cell Neurosci 2003;24:171-89.

58. Tong J, Latzman JM, Rauch J, Zagzag DS, Huang JH, Samadani U. Sonic hedgehog agonist fails to induce neural stem cell precursors in a porcine model of experimental intracranial hemorrhage. Acta Neurochir Suppl 2011;111:151-4.

59. Yamashita T, Ninomiya M, Acosta PH, García-Verdugo GM, Sunabori T, Sakagu-Chi M, et al. Subventricular zone-derived neuroblasts migrate and differentiate into mature neurons in the post-stroke adult striatum. J Neurosci 2006;26:6627-36.

60. Tyagi V, Theobald J, Barger J, Bustoros M, Bayin NS, Modrek AS, et al. Traumatic brain injury and subsequent glioblastoma development: Review of the literature and case reports. Surg Neurol Int 2016;7:78.

61. Coussens LM, Werb Z. Inflammation and cancer. Nature 2002;420:860-7.

62. Buffo A, Rite I, Tripathi P, Lepier A, Colak D, Horn AP, et al. Origin and progeny of reactive gliosis: A source of multipotent cells in the injured brain. Proc Natl Acad Sci USA 2008;105:3581-6.

63. Lang B, Liu HL, Liu R, Feng GD, Jiao XY, Ju G. Astrocytes in injured adult rat spinal cord may acquire the potential of neural stem cells Neuroscience 2004;128:775-83.

64. Hopewell JW. The subependymal plate and the genesis of gliomas. J Pathol 1975; 117:101-3.

65. Vick NA, Lin MJ, Bigner DD. The role of the subependymal plate in glial tumorigenesis. Acta Neuropathol 1977;40:63-71.

66. Friedmann-Morvinski D, Bushong EA, Ke E, Soda Y, Marumoto T, Singer $\mathrm{O}$, et al. Dedifferentiation of neurons and astrocytes by oncogenes can induce gliomas in mice. Science 2012;338:1080-4.

67. Marumoto T, Tashiro A, Friedmann-Morvinski D, Scadeng M, Soda Y, Gage FH, et al. Development of a novel mouse glioma model using lentiviral vectors. Nat Med 2009;15:110-6.

68. Barnabé-Heider F, Göritz C, Sabelström H, Takebayashi H, Pfrieger FW, Meletis $\mathrm{K}$, et al. Origin of new glial cells in intact and injured adult spinal cord. Cell Stem Cell 2010;7:470-82.

69. Carlén M, Meletis K, Göritz C, Darsalia V, Evergren E, Tanigaki K, et al. Forebrain ependymal cells are Notch-dependent and generate neuroblasts and astrocytes after stroke. Nat Neurosci 2009;12:259-67.

70. Adeberg S, König L, Bostel T, Harrabi S, Welzel T, Debus J, et al. Glioblastoma recurrence patterns after radiation therapy with regard to the subventricular zone. Int J Radiat Oncol Biol Phys 2014;90:886-93.

71. Bohman LE, Swanson KR, Moore JL, Rockne R, Mandigo C, Hankinson $\mathrm{T}$, et al. Magnetic resonance imaging characteristics of glioblastoma multiforme: Implications for understanding glioma ontogeny. Neurosurgery 2010;67:1319-28.

72. Chaichana KL, McGirt MJ, Frazier J, Attenello F, Guerrero-Cazares H, Quinones-Hinojosa A. Relationship of glioblastoma multiforme to the lateral ventricles predicts survival following tumor resection. J Neuro Oncol 2008;89:219-24

73. Barres BA. The mystery and magic of glia: A perspective on their roles in health and disease. Neuron 2008;60:430-40.

74. Robel S, Berninger B, Gotz M. The stem cell potential of glia: Lessons from reactive gliosis. Nat Rev Neurosci 2011;12:88-104.

75. Sofroniew MV, Vinters HV. Astrocytes: Biology and pathology. Acta Neuropathol 2010;119:7-35

76. Laird MD, Vender JR, Dhandapani KM. Opposing roles for reactive astrocytes following traumatic brain injury. Neurosignals 2008;16:154-64.

77. Katz AM, Amankulor NM, Pitter K, Helmy K, Squatrito M, Holland EC. Astrocyte-specific expression patterns associated with the PDGF-induced glioma microenvironment. PLoS One 2012;7:e32453.

78. Liu C, Sage JC, Miller MR, Verhaak RG, Hippenmeyer S, Vogel H, et al. Mosaic analysis with double markers reveals tumor cell of origin in glioma. Cell 2011;146:209-21.

79. Johnson VE, Stewart JE, Begbie FD, Trojanowski JQ, Smith DH, Stewart W. Inflammation and white matter degeneration persist for years after a single traumatic brain injury. Brain 2013;136:28-42.

80. Liao Y, Liu P, Guo F, Zhang ZY, Zhang Z. Oxidative burst of circulating neutrophils following traumatic brain injury in human. PLoS One 2013;8:e68963.

81. Murray KN, Parry-Jones AR, Allan SM. Interleukin 1 and acute brain injury. Front Cell Neurosci 2015;9:18

82. Woodcock T, Morganti-Kossmann MC. The role of markers of inflammation in traumatic brain injury. Front Neurol 2013;4:18.

83. Kuperman DA, Schleimer RP. Interleukin-4, interleukin-13, signal transducer and activator of transcription factor 6, and allergic asthma. Curr Mol Med 2008;8:384-92.

84. Schwartzbaum J, Ahlbom A, Malmer B, Lönn S, Brookes AJ, Doss H, et al. Polymorphisms associated with asthma are inversely related to glioblastoma multiforme. Cancer Res 2005;65:6459-65.

85. Curran CS, Bertics PJ. Eosinophils in glioblastoma biology. J Neuroinflammation 2012;9:11.

86. Fredens K, Dahl R, Venge P. The Gordon phenomenon induced by the eosinophil cationic protein and eosinophil protein X. J Allergy Clin Immunol 1982;70:361-6.

87. Yang D, Chen Q, Su SB, Zhang P, Kurosaka K, Caspi PP, et al. Eosinophil-derived neurotoxin acts as an alarmin to activate the TLR2MyD88 signal pathway in dendritic cells and enhances Th2 immune responses. J Exp Med 2008;205:79-90.

88. Grauer OM, Molling JW, Bennink E, Toonen LW, Sutmuller RP, Nierkenset S, et al. TLR ligands in the local treatment of established intracerebral murine gliomas. J Immunol 2008;181:6720-9.

89. Curtin JF, Liu N, Candolfi M, Xiong W, Assi H, Yagiz K, et al. HMGB1 mediates endogenous TLR2 activation and brain tumor regression. PLoS Med 2009;6:e10.

90. Mossman BT. Introduction to serial reviews on the role of reactive oxygen and nitrogen species (ROS/RNS) in lung injury and diseases. Free Radic Biol Med 2003;34:1115-6.

91. Sipos F, Firneisz G, Muzes G. Therapeutic aspects of c-MYC signaling in inflammatory and cancerous colonic diseases. World J Gastroenterol 2016;22:7938-50

92. Fang WH, Wang DL, Wang F. Expression of c-Myc protein on rats brains after concussion, FaYi Xue Zha Zhi 2006;22:333-4.

93. Wan C, Jiang J, Mao H, Cao J, Wu X, Cui G. Involvement of upregulated p53-induced death domain protein (PIDD) in neuronal apoptosis after rat traumatic brain injury. J Mol Neurosci 2013;51:695-702.

94. Ohana N, Benharroch D, Sheinis D, Cohen A. Traumatic glioblastoma: Commentary and suggested mechanism. J Int Med Res 2018;46:2170-6. 
95. Xiong Y, Peterson PL, Lee CP. Alterations in cerebral energy metabolism induced by traumatic brain injury. Neurol Res 2001;23:129-38.

96. Arif T, Krelin Y, Nakdimon I, Benharroch D, Paul A, Dadon-Klein D, et al. VDAC1 is a molecular target in glioblastoma, with its depletion leading to reprogrammed metabolism and reverse oncogenic properties. Neuro Oncol 2017;19:951-64.

97. Khan M, Khan H, Singh I, Singh AK. Hypoxia inducible factor 1 a stabilization for regenerative therapy in traumatic brain injury. Neural Regen Res 2017;12:696-701.

98. Higashida T, Kreipke CW, Rafols JA, Peng C, Schafer S, Schafer P, et al. The role of hypoxia inducible factor 1-a, aquaporin-4 and matrix metalloprotein-9 in blood-brain-barrier disruption and brain edema after traumatic brain injury. J Neurosurg 2011;114:92-101.

99. Benharroch D, Osyntsov L. Infectious diseases are analogous with cancer. Hypothesis and implications. J Cancer 2012;3:117-21.

100. Kappler M, Tauber H, Schubert J, Vordermark D, Eckert AW. The real face of HIF $1 \mathrm{a}$ in the tumor process. Cell Cycle 2012;11:3932-6.

101. Palsson-McDermott EM, O'Neil LA. The Warburg effect then and now: From cancer to inflammatory diseases. Bioessays 2013;35:965-73. 